\title{
FORMAÇÃO DE CONCEITOS NO ENSINO DE LÍNGUA MATERNA: \\ O PRINCÍPIO DA FUNCIONALIDADE
}

\author{
Vaima Regina Alves Lemos
}

\section{RESUMO}

Este artigo visa a examinar aspectos da perspectiva vygotskiana sobre a formação de conceitos no que tange a sua importância para a ação pedagógica no ensino de línguas. Propõe-se uma releitura do desafio de ensinar português como língua materna a partir de uma experiência vivida em uma escola pública do município de Cruz Alta-RS, no ano de 2004. O problema didático focalizado foi o ensino do emprego adequado dos principais sinais de pontuação. $O$ trabalho busca ainda estabelecer um elo entre a teoria visitada e a experiência pedagógica relatada, ou seja, dar conta das questões suscitadas em nível teórico-prático.

\section{INTRODUÇÃO}

Este artigo começa procedendo a uma sucinta apresentação da perspectiva vygotskiana sobre a formação de conceitos, com ênfase na sua importância para a ação pedagógica. Na seqüência, apresenta-se uma visão sobre o trabalho de ensino de português como língua materna a partir de uma experiência vivida em uma escola pública do município de Cruz Alta-RS, no ano de 2004. O problema didático focalizado foi o ensino do emprego adequado dos principais sinais de pontuação. $O$ trabalho conclui buscando estabelecer um elo entre a teoria visitada e a experiência pedagógica relatada, seguido de uma breve síntese final.

\section{VYGOTSKY E A FORMAÇÃO DE CONCEITOS}

Pensar a construção do conhecimento em língua materna, intenção do presente trabalho, implica considerar como fator determinante de uma reflexão promissora sobre esse assunto, os estudos de Vygotsky sobre a formação de conceitos.

Em sua obra "Pensamento e Linguagem"(1993), o autor apresenta registros de pesquisas sobre como se processa a formação dos conceitos e as etapas que se antepõem a esta efetivação: o chamado pensamento por complexos. 
Esse tipo de pensamento caracteriza a diferença entre pensamento infantil e adulto e revela um nível em que não há apenas "impressões subjetivas" (p.53), mas associações baseadas em relações factuais entre os elementos que fazem parte de determinada tarefa. Essa etapa de "pensamento por complexos" é composta por cinco tipos: associativo / coleções / em cadeia / difuso e pseudoconceito. Cada um deles, mesmo com manifestações diferentes do exercício de conexões, manifesta a elaboração interna no avanço para a construção dos conceitos propriamente ditos.

O próprio autor admite que não só a criança, mas também o adulto, em diversas condições, pensa por complexos, pois não é possível uma pessoa "transmitir" a outra uma forma de pensar acabada. É necessário que dados sejam fornecidos para que o interlocutor forme complexos em torno deles até chegar a um conceito sobre a informação. Isso revela uma atividade complexa que envolve as seguintes funções básicas intelectuais: associação, formação de imagens, atenção, inferência e tendência determinante ( existência de uma questão a ser selecionada).

É um processo mediado, de investimento particular, no qual a palavra (signo) desempenha função diretiva, conduzindo as operações mentais e controlando o curso dessas operações:

\begin{abstract}
A formação de conceitos é o resultado de uma atividade complexa, em que todas as funções básicas tomam parte. No entanto, o processo não pode ser reduzido à associação, à atenção, à formação de imagens, à inferência ou às tendências determinantes. Todas são indispensáveis, porém insuficientes sem o uso do signo, como o meio pelo qual conduzimos as nossas operações mentais, controlamos o seu curso e as canalizamos em direção à solução do problema que enfrentamos. (Vygotsky, 1993, p. 50 )
\end{abstract}

Nesse avanço do raciocínio lógico-abstrato constitui-se um ponto-chave a seqüência "síncrese, análise e síntese", que é a evolução de um pensamento sincrético (baseado em percepções difusas) para um pensamento sintético, com informações organizadas a partir da análise de certa realidade ou características perceptíveis e comprováveis logicamente.

Com base nesses estudos de Vygotsky é possível confirmar o papel da escola e dos educadores na construção do conhecimento. A postura do professor deve ser de investigador, criando desafios que confrontem a vontade e o intelecto do aluno com 
uma necessidade a ser suprida. A condução da aula conforme os conhecimentos específicos elaborados em cada área de ensino deve proporcionar a elaboração de complexos e a construção de conceitos, respeitando a essência dessa construção na condição humana. Propiciar as etapas da estruturação do conhecimento é ser coerente com essa condição, garantindo o desenvolvimento do ser a partir da elaboração de saberes.

\section{O TRABALHO COM LÍNGUA MATERNA}

Como muitos autores afirmam, cabe à escola, principalmente no que tange à língua portuguesa, capacitar o aluno ao domínio da norma padrão. Mas não como uma subserviência à língua literária, utilizada por autores famosos do passado; e sim como a habilidade geral que permita ao aluno fazer uso de uma linguagem adequada às diferentes circunstâncias do cotidiano. Para isso, o trabalho em sala de aula deve colaborar para que o aluno se torne:

Cada vez mais consciente de que a escolha dos elementos da língua para construir textos não é fortuita, mas regida pela adequação do recurso lingüístico e das instruções de sentido que contém aos propósitos dos usuários da língua em cada situação de comunicação. (Travaglia, 1997, p. 151)

Para isso é inviável uma proposta que trate apenas de exercícios envolvendo nomenclaturas ou que conduza o processo através da exposição oral de idéias prontas sobre determinado tópico lingüístico.

Não seria o caso de descartar o estudo da gramática nas aulas de Educação Básica, mas de empregar uma metodologia que proporcione o exercício das possibilidades gramaticais através do emprego comparativo, seja a partir da análise do respeito a determinadas convenções gramaticais ou na ausência deles. Atividades dessa natureza remetem o aluno à observância dos resultados semânticos obtidos através das seleções de uso feitas em dado contexto, o que conduz à compreensão dos fenômenos envolvidos.

Gentner \& Medina (1998) defendem que mesmo entre adultos existe uma mistura do processamento baseado na comparação com o baseado em regras. Afirmam, também 
que, estando o conhecimento abstrato já constituído, processos de "alinhamento" são necessários para que aconteça o repasse desses conhecimentos para novas situações.

Essa é uma postura reflexiva que usa os efeitos da linguagem para a análise de seu registro escrito, impedindo a falta de compromisso com a busca do padrão sem considerá-lo mera erudição; mas, sim, domínio social, como também evitando o uso exclusivo da nomenclatura, trabalho árduo e infrutífero.

\section{UMA PRÁTICA DE SALA DE AULA}

A aplicação profícua em aula da teoria anteriormente exposta foi comprovada em uma turma composta por 24 alunos, concluintes do Ensino Médio de uma Escola Estadual (EJA) de Cruz Alta no ano de 2004.

Tendo sido constatada, através das produções escritas e de testemunhos dos alunos, insegurança da turma quanto ao emprego dos sinais de pontuação, ao usá-los na maioria das vezes de forma aleatória, sem nenhuma lógica sintática ou semântica, foi proposto, então, um trabalho em que os alunos pudessem refletir sobre o efeito produzido na interpretação de passagens sem pontuação alguma e a dificuldade de atribuir sentido à seqüência de termos da oração.

Sem dúvida, a atividade é simples. Mas promove um processo mental ativo, pois instiga o aluno a experimentar e a buscar saídas na solução de um problema de linguagem, percebendo que os sinais de pontuação não são apenas convenções sintáticas, mas recursos capazes de colaborar significativamente para a compreensão das produções escritas.

Entre as várias situações apresentadas para os alunos estava a conhecida frase "Um fazendeiro tinha um bezerro e a mãe do fazendeiro era também o pai do bezerro." Não só na busca da significação dessa frase, mas também diante dos demais desafios, ilustrou-se, através da oralização dos alunos e das discussões mantidas com os colegas, o papel interpretativo-crítico, para o professor, de todo o processo conceitual 
teorizado por Vygotsky, por ocasião do acompanhamento dos alunos no empenho de solucionar cada questão.

Várias outras atividades foram propostas ao longo do período, envolvendo inclusive os textos dos próprios alunos, os quais, depois de um certo período, revelaram melhor desempenho nesse tópico lingüístico e, principalmente, maior consciência das opções feitas durante a produções em sala de aula.

\section{PONTOS DE ENCONTRO}

Viver a gramática em aula independe de grandes projetos. Porém é de fundamental importância que o professor de português seja capaz de reconhecer três fatores importantes nessa ação pedagógica: a) o processo intelectual envolvido no ensinoaprendizagem, no caso, a formação de conceitos; b) a natureza do tópico lingüístico e suas peculiaridades de ensino; e c) a realidade da turma de educandos e todas as características de ação que a variação de realidades implica.

Se a atuação pedagógica for capaz de contemplar essa triangulação, é possível proporcionar o avanço no domínio da língua-padrão através do exercício de um importante aspecto da cognição humana: a formação de conceitos.

\section{CONSIDERAÇÕES FINAIS}

Capacitar o aluno de Educação Básica a usar com propriedade a língua padrão é uma tarefa escolar e exige do professor de Português uma reflexão sobre todos os fatores envolvidos no ensino-aprendizagem. A partir da postura crítica sobre a realidade escolar e lingüística e do domínio teórico-prático dos processos intelectuais, é possível ao profissional do ensino de línguas construir uma prática reflexiva, tanto para ele como para os alunos, que facilitará o aperfeiçoamento da competência comunicativa de seus tutorados em um trabalho consciente. 
Para isso, o docente encontra em Vygotsky e sua teoria na formação de conceitos um suporte fundamental para toda atividade escolar do mesmo gênero daquela que pudemos vivenciar e ora relatamos no presente trabalho.

\section{BIBLIOGRAFIA}

GENTNER, Dedre; MEDINA, José. Similarity and development os categories , In: Cognition 65. Elsevier Science, 1998.

TRAVAGLIA, Luiz Carlos. Gramática e Interação: uma proposta para o ensino de gramática no $1^{\circ} \mathbf{e} 2^{\circ}$ graus. 2 ed. São Paulo: Cortez, 1997.

ROCHA, Luiz Carlos . Gramática nunca mais.Minas Gerais: Editora UFMG, 2002.

VYGOTSKY, L.S. Pensamento e Linguagem. São Paulo: Martins Fontes, 1993. 